\title{
Images
}

\section{Endovaskuläre Therapie}

\section{Multilayer-Stent erfolgreich bei Aneurysma in der Popliteal-Arterie eingesetzt}

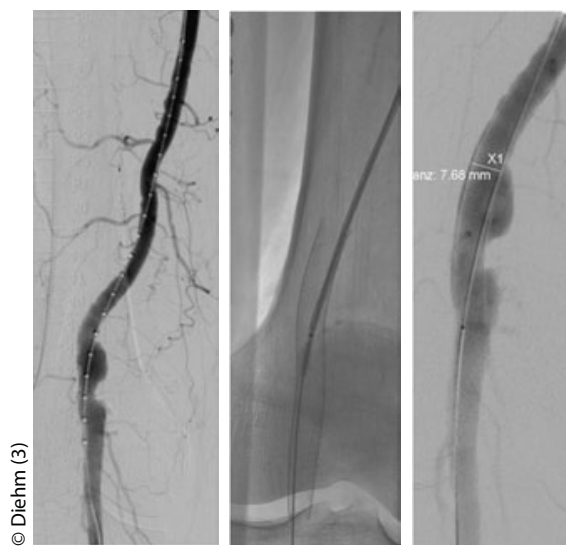

Abb. 1 Links: Angiografische Darstellung des Lumens eines 2,6 cm großen Aneurysmas des femoropoplitealen Übergangs; Mitte: Insertion zweier Multilayer-Stents; rechts: Angiografie nach der Stentimplantation.

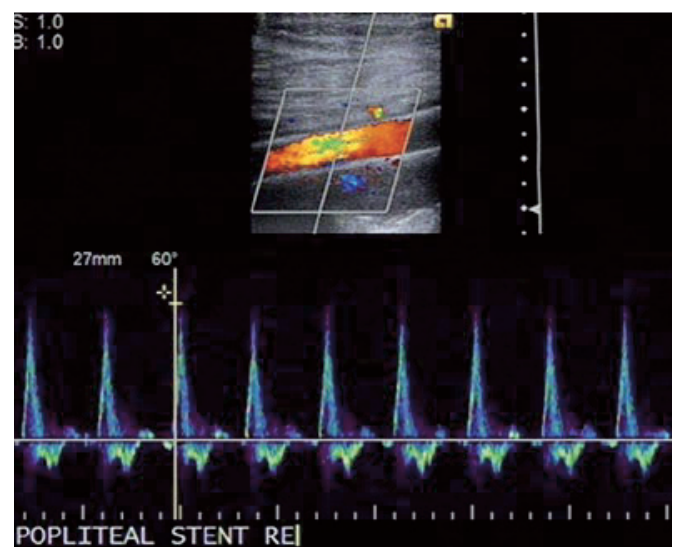

Abb. 2 Duplexsonografischer Längsschnitt des mit einem Multilayer-Stent behandelten Aneurysmas am ersten postinterventionellen Tag. Der Stent ist frei perfundiert.

diatis) im Bereich der aneurysmatischen Arterie implantiert (Abb. 1, Mitte und rechts).

Schon am ersten postinterventionellen Tag zeigt die duplexsonografische Kontrolle (Abb. 2 und 3), dass das Aneurysma außerhalb des Stents thrombosiert ist, während das Stentlumen frei perfundiert ist.

Der Patient konnte am ersten postinterventionellen Tag nach Hause entlassen werden. Im Rahmen der Kontrolle nach sechs Monaten war der Patient asymptomatisch und das Aneurysma sonografisch weiterhin ausgeschaltet.

\section{Kommentar}

Das Design des Multilayer-Stents reduziert die Flussgeschwindigkeit außerhalb des Stents im Aneurysma, während es den laminaren Fluss im Bereich des Gefäßlumens erhält. Hierdurch kommt es zu einer Reduk-

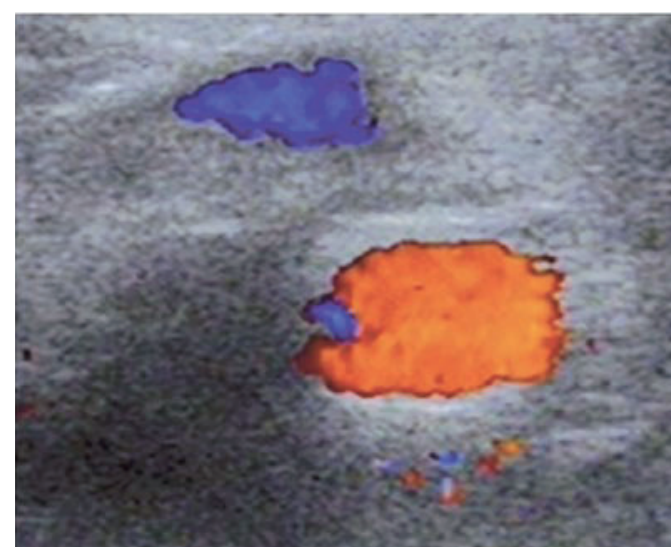

Abb. 3 Duplexsonografischer Querschnitt des gestenteten Poplitealaneurysmas einen Tag postinterventionell. Es findet sich kein arterieller Fluss außerhalb des Stents als Ausdruck der Thrombosierung des Aneurysmas außerhalb des Stentlumens.

moralarterie durchgeführte diagnostische Angiografie (Abb. 1, links) bestätigte den sonografisch erhobenen Befund.

Nach Ausmessung der Größenverhältnisse werden zwei Multilayer-Stents (Car-

tion des Drucks im Aneurysmasack, der schlussendlich zu einer Stase und der Ausbildung eines organisierten Thrombus führt.

Erste Erfahrungen mit dieser neuen Technologie, nicht nur in der Behandlung von Aneurysmen im femoropoplitealen Gefäßsegment, sind vielversprechend. Langzeiterfahrungen stehen allerdings noch aus.

Korrespondenzadresse: PD Dr. med. Nicolas Diehm

Klinische und Interventionelle Angiologie Schweizerisches Herz- und Gefäßzentrum Inselspital, Universität Bern $\mathrm{CH}-3010$ Bern 